Transportation Research Forum

The Effects of Safety Practices, Technology Adoption, and Firm Characteristics on Motor Carrier Safety

Author(s): Sarah J. Dammen

Source: Journal of the Transportation Research Forum, Vol. 44, No. 1 (Spring 2005), pp. 103-120

Published by: Transportation Research Forum

Stable URL: http://www.trforum.org/journal

The Transportation Research Forum, founded in 1958, is an independent, nonprofit organization of transportation professionals who conduct, use, and benefit from research. Its purpose is to provide an impartial meeting ground for carriers, shippers, government officials, consultants, university researchers, suppliers, and others seeking exchange of information and ideas related to both passenger and freight transportation. More information on the Transportation Research Forum can be found on the Web at www.trforum.org. 


\section{The Effects of Safety Practices, Technology Adoption, and Firm Characteristics on Motor Carrier Safety}

The theory of the firm suggests that firms should maximize profit by investing in safety until marginal cost is equal to the marginal benefit. This paper addresses motor carrier safety from the perspective of the firm, developing the theoretical framework for firm safety decisions. Additionally, this paper tests the relationship between firm safety performance and safety practices, new safety technologies, and firm marketing strategies. By testing the impact of the safety performance marketing strategy on carrier accident rates, it can be shown that firm managers have control over the safety performance of their firms through management decisions.

\section{by Sarah J. Dammen}

Safety in the motor carrier industry has been a topic of public concern dating to the infancy of the industry. Since that time, the U.S. motor carrier industry has undergone many structural, technical, and regulatory changes. Government safety regulations, safety-related technologies, and firm safety practices have evolved, producing a general trend of improved safety in transportation industries (McCarthy, 2001, pp. 564-566).

Economic deregulation of the motor carrier industry gave rise to a wealth of economic literature focusing on the safety effects of deregulation. Within this literature, areas of concern include the effect of new entrants, the effect of declining profitability due to increased competition (the profit-safety relationship), and mode shifting. Research since deregulation has focused on the physical conditions in the causation of accidents, driver characteristics, and government safety regulations. Research focused on carrier management policies and firm safety behavior, an exception being Corsi and Fanara (1988) has been less common.

How do firms make safety-related decisions? The theory of the firm suggests that firms should invest in safety practices and technologies until marginal cost is equal to the marginal benefit of the reduction in the carrier accident rate. The theoretical framework of this paper proposes that in the face of uncertainty regarding the occurrence of vehicle accidents, firms maximize expected profit by choosing an optimal output level and an optimal mix of safety inputs.

This paper adds to the economic literature on motor carrier safety addressing motor carrier safety from the firm perspective. In a fashion similar to Corsi and Fanara (1988), it is the underlying premise of this paper that firms have a direct impact on their accident rate. Firm managers influence their accident rate through safety practices and safety technology adoption, given their firm characteristics. Firm management policies and marketing strategies demonstrate that firm managers can target and successfully impact their carrier's accident rate. Government safety regulations alone may not be the most effective means for reducing truckrelated crashes. This paper advocates focusing on the behavior of the firm and firm incentives to adopt new safety technology for increasing motor carrier industry safety. With the increasing industry and government focus on motor carrier safety and security, it is necessary to add research on the topic and to evaluate the impact of technology, firm practices and government regulations on industry safety.

The empirical section of this paper tests the effects of safety practices, technologies, and firm characteristics on the carrier injury and fatality accident rates. Safety practices include safety meetings, firm speed limit, motorist "call-in" number, and apprenticeship training programs. Firm characteristics tested in this paper are: 
firm size, less-than-truckload (LTL) carriers, use of owner-operators, unionization, the firm marketing strategies, on-time performance, and safety performance.

\section{BACKGROUND AND LITERATURE}

Lave (1968) focused on the role of government in providing transportation safety. Asserting, "We can be too safe," he goes on to make the case that safety is a scarce resource (p. 512). This article is noteworthy for a discussion on transportation safety because it is one of the first articles on the subject and it clearly identifies transportation safety as an economic good; there are tradeoffs required to achieve higher levels of safety.

Lave indirectly questions whether there was too much safety provided in the regulated transportation industries, because train, bus, and air passenger-fatality rates were all significantly lower than private automobile passenger-fatality rates. If regulated freight rates were above the competitive levels that would have existed in a non-regulated industry, economic regulation may have induced safety spending above the level firms would have chosen in a competitive environment. Specifically, rate-of-return regulation likely resulted in over-investment in capital (Traynor \& McCarthy, 1991).

Although academic research as early as the 1950 s demonstrated that regulation created inefficiencies and significant rents to transportation industries, it was not until 1980 that deregulatory legislation became law. President John F. Kennedy supported deregulation in 1962, however the movement toward deregulation faced strong opposition by the Teamsters and industry groups such as the American Trucking Association (ATA), stalling deregulation efforts until the late 1970s. Greater social acceptance of market forces provided the support needed to begin the gradual process of market deregulation. The first movement toward deregulation occurred in 1975 when the ICC modified rules to promote more competition in the trucking industry. By 1979, the ICC had eliminated rules that prevented competition between contract and common carriers. Following this move, the ICC proposed "relaxing entry standards and freeing rates for a significant portion of the trade" (Moore, 2002, p. 7). The Motor Carrier Regulatory Reform and Modernization Act of 1980 (MCA) significantly deregulated the motor carrier industry, however complete deregulation of the industry did not occur until the mid 1990s when the ICC was abolished. As a result of the MCA, real rates for shippers decreased, many new firms entered the trucking industry, and there was a dramatic decrease in industry profit. Perhaps the most controversial public issue concerning deregulation of the motor carrier industry and the passage of the MCA were the safety effects of the impending deregulation (Moore, 2002).

Along with the passage of the MCA came an explosion of deregulation literature, including safety-deregulation literature. Prominent topics in the deregulation-safety literature include the effect of new entrants and the profit-safety relationship. The new-entrants literature focused on the increased entry of small new firms and the occurrence of "fly-by-night" firms. New firms with inexperienced managers, young and inexperienced drivers, along with the lack of financial backing were thought to pose the most serious threats for decreased industry safety. The profit-safety relationship literature focuses on the safety effects because of declining profits. It was believed that increased competition would cause firms to "cut corners" particularly with regard to maintenance and safety expenditures.

The preeminent source for deregulationsafety articles and a complete bibliography is the book, Transportation Safety in an Age of Deregulation, edited by Moses and Savage (1989). Papers in this book are from a deregulation and safety conference at the Transportation Center of Northwestern University. Examples include Adams (1989), Boyer (1989), and Hauer (1989). Both sides of the deregulation-safety issue are presented, along with chapters discussing the theoretical underpinnings of safety-deregulation arguments. This book covers both the airline and motor carrier industry, and addresses the profitsafety relationship, new entrants, congestion, as well as mode shifting.

Profit-safety literature is strongly connected to the literature on the safety effects of industry deregulation, circa the late 1970s and 1980. One of the more significant and recent papers 
concerning the profit-safety relationship in the trucking industry is Beard (1992). Beard finds evidence that supports the profit-safety relationship; more-profitable carriers are safer. Beard criticizes previous research attempts for data problems and use of wrong measures for safety and financial condition. He uses roadside safety inspection data as a proxy for firm safety. Beard uses a cash-flow method to evaluate risky firms and probit model to test the profit-safety relationship (with the dependent being the probability a vehicle is taken out of service upon inspection). Mixon and Upadhyaya (1996) provide a note on Beard's 1992 paper. Using the same data and a two-stage least squares approach, they test the relationship between carrier accident rates and asset specificity and firm size.

Corsi and Fanara (1989) is a key study on the safety effects of new entrants. Examining new entrants versus established carriers in the years 1980-1984, their study finds that new entrants have accident rates between $27 \%$ and $33 \%$ higher than the average accident rate for the established carriers. For the " "newest' of the new entrants," the accident rate is nearly $70 \%$ higher than the average established carrier (p. 255). The safety effect of new entrants following deregulation may have been masked in aggregate studies because of the relatively small size of new firms and increasing safety from technology and safety regulations. Thus, in addition to new entrants, deregulation had a firm size effect.

Overall, the literature remains mixed as to the impact of deregulation on motor carrier safety. Traynor and McCarthy (1991, 1993), using aggregate California highway accident data, found that highway safety is independent of the economic environment and safety actually improved in the years following deregulation. Alexander (1992) finds that fatality and injury rates are lower, but the collective accident rate was unaffected by deregulation. Alexander goes on to recommend that safety expenditures at the firm level should be examined to see the change in safety inputs after deregulation, but he also notes there is a lack of data. Corsi et al (1988) finds "no significant increase" in accident rates during transition years, but does find that "certain management policies and practices do have a statistically significant impact on carrier accident rate." Among the management policies that should be monitored are increased use of owner-operators, equipment age and changes in carrier insurance premiums.

Evidence supporting the negative safety effects of deregulation is found in the analysis by Daicoff (1988), who finds that safety was improving prior to deregulation, and safety continued to improve after deregulation but at a slower rate. Chow (1989) finds little evidence between financial condition and safety-related activities, but notes, "as financial fitness improved, equipment was replaced [more often] and less use was made of owneroperators" (p. 239). Using this evidence to conclude deregulation had a negative impact on safety assumes that use of owner-operators is negatively related to carrier safety and that equipment age is a significant factor in accidents. The strongest evidence of the negative safety effects due to deregulation is the effect of new entrants, who had dramatically higher accident rates in the first few years after the passage of the MCA compared to the established carriers (Corsi \& Fanara, 1989).

With no clear consensus on the safety effects of deregulation, one may cautiously conclude that deregulation had very little to no effect on safety. The mixture of results in the literature is primarily due to the poor quality accident data and the gradual time span over which deregulation occurred. In addition there were "significant changes in vehicle technology and important safety regulation changes in the early years following the MCA 1980" that likely impacted safety performance of the industry (Moses \& Savage, 1989, p. 218).

The economic literature on motor carrier safety since the height of the deregulation research is increasingly focused on factors related to crashes and government safety regulations. The literature on crash-related factors can be further divided into physical factors (environment, road type, vehicle type, etc.), firmrelated characteristics, and driver characteristics. There are numerous government, industry, and engineering studies examining the physical and mechanical aspects of truck crashes, whereas the economics literature focuses on firm and driver characteristics. The economics literature also 
addresses driver and carrier compliance with government regulations and the effectiveness of government safety programs.

Monaco and Williams (2000) focus on the relationship between safety performance and carrier and driver characteristics. Using driver survey data, the analysis focuses on three dependent variables, occurrence of an accident, moving violation, and logbook violation. Occupational characteristics are found to be more significant than driver demographic characteristics. Kaneko and Jovanis (1992) find that the patterns of driving during multi-day hauls can significantly increase the accident risk during the eighth day. Additionally, the number of consecutive hours of driving is associated with higher accident risk.

Corsi, Fanara, and Roberts (1984) examine the relationship between carrier accident rates and compliance with various safety regulations. Interestingly, they find that non-compliance with hours-of-service regulation is negatively related to carrier accident rates, while non-compliance with other safety regulations are all positively related to carrier accident rates. Both firm size and use of owner-operators are negatively related to accident rates. The hours-of-service regulation has received considerable attention in the literature and continues to be an area of interest due to the 2003 hours-of-service rule change. Some articles examining the role of hours-ofservice and safety are: Saltzman and Belzer (2002), and Williams and Monaco (2001).

Moses and Savage (1994) also find that carrier safety performance is correlated with compliance with hours-of-service regulations. Additional findings show reduced crash risk related to firm size, and firms that are private carriers (not for-hire). Contrary to the authors' previous research (Moses and Savage 1992), older firms do not necessarily have higher crash rates; firm age does not appear to be related to crash rates.

Corsi and Fanara (1988) advocate a management perspective in addressing firm safety. They argue that managers "have a direct impact on their accident rate" (p. 154). Driver management policies which result in driver turnover rates are of particular interest and the authors find that driver turnover rates significantly increase carrier crash rates. Mejza et al. (2003) examine management policies and safety performance, specifically looking at hiring practices, driver training, driving rewards, and driver compliance with safety regulations.

"The findings imply that the safest trucking firms apply screening criteria consistently in all driver-hiring situations; emphasize pre-service and in-service training for company drivers and owner-operators alike; cover a broad scope of topics in several venues during the training programs and use several methods to evaluate drivers in those programs; and use an array of different types of rewards to support drivers who demonstrate safe driving performance" (p. 16).

\section{THEORY}

This paper approaches the topic of motor carrier safety from the firm perspective. It is therefore appropriate that the theory of the firm be used as the general theoretical framework. Following the theory of the firm is discussion of the theory of the relationship between motor carrier crash rates and safety inputs and firm characteristics.

Motor carrier safety starts with the firm. While government safety regulations attempt to ensure a minimum level of highway safety-in the form of highway laws and enforcement, provision of infrastructure and motor carrier safety inspections-ultimately, most trucking safety investment decisions are made at the firm level. Government safety regulations attempt to discourage or promote certain firm behavior. Following the basic tenants of the theory of the firm, firms act to maximize profit and will invest in safety inputs until the marginal cost of an additional unit of a safety input is equal to the marginal benefit. Maintenance activities, vehicle-based safety technologies, and driver training programs are all examples of firm investments that may increase their firm safety record.

Uncertainty-in many forms-plagues the decisions made by economic agents. Thus, a firm must take into account sources of uncertainty 
and proceed in making input and quantity-output decisions by maximizing expected profit. In the motor carrier industry, one major source of uncertainty is the occurrence of highway crashes. Though firms will engage in many safety practices and make safety investments to reduce their firm crash rate, some crashes will be outside the control of firms and their drivers.

Assuming the motor carrier industry is perfectly competitive, the firm is a price-taker. It is further assumed that safety performance of the firm has no noticeable effect on price. Price may be a function of firm characteristics, such as the type of commodity hauled, and whether the carrier is a less-than-truckload (LTL) or truckload (TL) carrier. The firm maximizes expected profit by choosing the level of non-safety inputs, $x$, and the amount of safety inputs, s. Output $q(x)$, is a function of non-safety inputs. While firms face numerous sources of uncertainty, the model will explicitly consider the probability of having an accident, $(1-\mathrm{G}(\mathrm{s} ; \gamma))$, per unit of output.

The firm's expected profit (Z) contains the vector of firm characteristics, $(\gamma)$ and the cost function depends upon the level of inputs (non-safety and safety related), and the price of inputs, w, given the firm characteristics. Damage expenses resulting from an accident are described by the function, $\mathrm{D}(\gamma)$, which depends upon a firm's characteristics. The firm should maximize the following expected profits $(\mathrm{Z})$ objective function:
Note that $\hat{s}$ is the random, critical variable and $\mathrm{s}$ is the known firm choice vector of safety inputs. $\mathrm{G}$ is a continuous, differentiable probability distribution function for the random variable $\hat{s}$ where $\hat{\boldsymbol{s}}$ represents a critical value of safety inputs, above which no accident occurs. $(1-\mathrm{G}(\mathrm{s} ; \gamma))$ is then the probability that an accident occurs, $\mathrm{P}(s \leq \hat{s} \mid \gamma)$. Thus as investment in safety inputs, $\mathrm{s}$, increases, the probability $\mathrm{P}(s \leq \hat{s} \mid \gamma)$ falls. Optimal output occurs at the level where the price is equal to the marginal cost of production, where marginal cost includes all the expected marginal costs of an accident.

Optimal safety investment, $\mathrm{s}^{*}$, occurs when the marginal cost of safety inputs is equal to the expected benefit of the safety inputs. Benefits in this model are gained from decreasing the probability of an accident (and thus lower costs from accidents). The safety performance of the firm, measured by the number of accidents, is the value of $\left(1-\mathrm{G}\left(\mathrm{s}^{*} ; \gamma\right)\right) * \mathrm{q}$.

Like the model put forth by Golbe (1986) for the airline industry, this theoretical framework does not suggest a relationship between the level of expected profit and safety performance. Financial condition of the firm could influence the safety performance of the firm in this model, if the financial standing of the firm is contained in the vector of firm characteristics.

While data limitations prevent explicit testing of the firm's safety input choices under expected profit maximization, the empirical section will

$$
\underset{x, s}{\operatorname{Max} \mathrm{Z}} P(\gamma) * q(x) \quad c(x, s, w ; \gamma) \quad(1 \quad G(s ; \gamma)) * D(\gamma) * q(x)
$$

$\mathrm{Z}$
$\mathrm{x}$
$\mathrm{s}$
$\gamma$
$\mathrm{w}$
$\mathrm{P}(\gamma)$
$\mathrm{q}(\mathrm{x})$
$\mathrm{C}(\mathrm{x}, \mathrm{s}, \mathrm{w} ; \gamma)$
$\mathrm{D}(\gamma)$
$(1-\mathrm{G}(\mathrm{s} ; \gamma))$

Profit

Output

Safety inputs

Firm type/firm characteristics

Wage rate

Price as a function of firm characteristics

Output

Cost as a function of output, safety inputs, and wages, given firm characteristics

Damage expenses as a function of firm characteristics

Probability of a crash per unit of output, as a function of safety inputs, given firm operating characteristics 
test the relationship between safety performance and safety inputs. Safety performance in this model will be the firm accident rate, A, defined as a function of the firm's safety inputs, s, given the firm's characteristics, $\gamma$.

\section{(2) $A=f(s ; \gamma)$}

Safety inputs are any safety-enhancing policy, practice, or technology. The safety practices used by firm managers should decrease their firm's crash rate. It is not clear if some of the safety practices are adopted retroactively. If so, firms with high accident rates may adopt safety practices with the hope that future accident rates will be lower.

Some safety practices may be more effective in reducing firm accident rates. For example, many accidents are caused by a combination of factors, with speed as a common component. Implementing a fleet speed limit would logically seem to have the ability to reduce firm accident rates. Specifically, a fleet speed limit should reduce crashes caused by speeding on the part of the truck. A fleet speed limit will not necessarily help to reduce all speed-related crashes, as other motorists may speed and the variation in the speed of traffic is a contributing factor to crashes. The impact of the safety practices is likely to vary by the quality of the particular practice.

Firm characteristics are common in motor carrier safety literature. Some firm characteristics seem to have strong theoretical reasons to suggest relationships with safety performance. Six firm characteristics will be tested in the empirical section. Each of these six variables will be introduced with a theoretical discussion to suggest a relationship between each firm characteristic and safety, along with the expected sign of the relationship, and any previous empirical results.

Firm size has consistently been inversely related to motor carrier crash rates (Corsi et al. 1984, Moses and Savage 1994). This has been explained by arguments that larger firms have an advantage with regard to fleet maintenance and training programs. They also have the financial means to invest in new technologies and often have large safety divisions to carry out firm safety policies and monitoring. Smaller firms may have difficulty in obtaining safety related information and limited capital resources to invest in safety technology.

Owner-operators are drivers that own their tractor and contract their services out to larger firms. Following principal-agent theory, owneroperators are likely to have lower crash rates because the drivers will ensure their safety and the continued operation of their tractor through careful driving and thorough knowledge of their vehicle operation and maintenance history. The principal-agent theory is tested by Mixon and Upadhyaya (1996). However, their paper looks at the ownership structure of the firm, not ownership of tractors or trucks by the drivers. Contrary to principal-agent theory, which suggests that owner-operators have safetyinducing incentives, Chow (1989) cites lower compensation for similar routes, and an inability to acquire resources needed for maintenance as reasons why owner-operators may have higher accident rates. In a highly competitive industry, owner-operators face conflicting pressure to ensure their own safety and their investment in their capital, while at the same time driving as many hours as possible under demanding schedules and avoiding additional expenditures on safety investments.

There have been no definitive results on the effect of unionization on firm safety performance. At the time of deregulation, the motor carrier industry was heavily unionized. New entrants and the need to cut labor costs after deregulation led to a decrease in the unionization of the industry. Given unions' goals of promoting worker safety and compensation, unions likely demand higher safety levels, reasonable route scheduling, and higher wages, all of which should reduce carrier crash rates. Monaco and Williams (2001) test union membership in their probit model, but only find a significantly negative relationship between union membership and moving violations; and they find the relationship between unions and accidents is insignificantly positive.

Trucking operations can be divided into the for-hire and private sectors. Within the for-hire industry there are two major segments: specialized carriers and general freight carriers. General freight carriers can be either truckload (TL) or less-than-truckload (LTL). Truckload carriers handle large shipments transported from one shipper to a single destination. 
Less-than-truckload operations often involve hub-and-spoke operations with many small shipments taken to terminals and distributed to many locations. The growth of the LTL segment has been fueled by technological advancements and the shift toward just-in-time (JIT) inventory systems. Specialized carriers often are required to have specialized equipment for hauling such commodities as petroleum, wood products, and hazardous materials. Specialized carriers tend to engage in truckload (TL) operations (McMullen, 2000, p. 142).

Chow (1989) contends that TL carriers "expose drivers to potentially longer and more irregular hours" (p. 225) because of the irregular turnaround and line-haul operations. Chow does not explicitly test LTL/TL carriers because his definition of type of carrier is based only on percentage of operations in intercity general commodity freight. Corsi and Fanara (1988, 1989) test general freight carriers versus carriers of other commodities and find that general freight carriers have higher crash rates. With relatively little previous research, the relationship between LTL carriers and firm accident rate is not clear. If one believes that LTL operations allow for more regular schedules and familiar routes, then LTL operations may reduce firm accident rates. However, LTL operations are often timesensitive, with time performance a top priority, which may lead LTL operations to increase firm accident rates, with the added difficulty of intercity operations contending with congested city streets and highways.

This paper will test the relationship between firm marketing strategy and firm accident rate. Two marketing strategies are included in the empirical section, on-time-performance (OTP) and safety performance (SAFESTRAT). In the fiercely competitive environment since deregulation, marketing strategies have developed within the motor carrier industry. Most commonly cited are the contrasting marketing strategies of on-time performance (OTP) and lowest-freight rate (LFR). An OTP marketing strategy will generally inflate operating costs because loads may not be full. The emergence of the OTP marketing strategy is the result of just-in-time inventory systems, consumer and shipper preference for fast deliveries, and is common for carriers of perishable or high-valued commodities. There is no clear expectation as to the relationship between either OTP and LFR and the firm accident rate, however both seem to have aspects that would tend to be related with higher accident rates. OTP requires demanding driver schedules, perhaps violating hours-ofservice requirements and creating an incentive to speed.

Firms with a safety-performance marketing strategy are likely to engage in safety enhancing activities in order to market their safety performance. Firms may provide shippers with information to demonstrate the high degree of safety investment and safety performance of the firm. For these reasons it is expected that there is a negative relationship between SAFESTRAT and carrier accident rate. Embodied within the SAFESTRAT variable is the underlying theory that firm management decisions have a direct impact on their accident rate. Firms have the control to improve their safety performance if so desired.

In approaching motor carrier safety from the perspective of the firm it is important to consider the firm choice variables, safety inputs, as well as the variables that economic theory and previous research deem to be significant. This section introduced the theoretical framework underlying the testing of safety practices, technology, and firm characteristics.

\section{DATA AND MODEL}

This study uses firm-level data for Class I and Class II motor carriers in 1996. Data used in this study was obtained from the Motor Carrier Safety, Operations and Technology (MSCOT) survey (US DOT 1999). The data set contains information on firm operating characteristics, safety practice and technology use, and carrier safety performance. While it is likely that more recent technology-use data have been collected, the use of the 1996 data provides estimates of the impact of safety measures in the 1990s and the safety effect of technologies by early adopters of the technologies and practices. Summary statistics for all variables estimated in the study are in Table 1.

Four of the firm characteristics variables are obtained from the annually reported motor carrier financial and operating statistics. Use of 
owner-operators (OOP) is created as the ratio of miles rented with driver to total highway miles. The UNION dummy variable is created as a ratio of health and welfare expenditures to total fringe expenditures. If this ratio is greater than 0.1 then UNION equals one, otherwise UNION is zero (Kerkvliet \& McMullen, 1997). Firm total assets, (reported in millions of dollars) is used as a proxy for firm size (SIZE). Carrier commodity type is used to identify those firms that are lessthan-truckload (LTL) carriers. The number of injury accidents and the number of fatal accidents are used to construct the dependent variables of the regressions.

The ATA, together with the National Private Truck Council, collected firm safety practice, technology, and marketing strategy data in the "Motor Carrier Safety, Operations and Technology Survey" (MCSOTS). This survey included questions on the use of selected information technology, including some safety related technology and the use of firm safety practices. Due to low adoption rates of technologies in 1996 and the fact that most of the technologies in the survey were information technologies, only three safety-related technologies are included in the empirical analysis: collision avoidance systems (COLLAV), automated vehicle diagnostics (DIAGN), and on-board computer monitoring (OBCMON). The safety practices used in this paper are: firm safety meetings (SAFEMEET), fleet speed limit (FLEETSPEED), and use of an apprenticeship-training program (APRENT).

On-board computers (OBC) record vehicle operation statistics through sensors and can present the information to drivers or management and dispatch in real-time or on a trip-by-trip basis. OBC information can be used to analyze vehicle performance, particularly fuel consumption, as well as speed, erratic maneuvering, and hard stops. While some OBCs are not designed specifically for safety monitoring (fuel consumption for example) the MSCOT survey specifically asked about the use of OBC for safety monitoring. Collision

Table 1: Descriptive Statistics

\begin{tabular}{lcccl}
\hline Binary Variables & & & & \\
& Mean & Std Dev & Count & Variable Description \\
COLLAV & 0.008 & 0.088 & 4 & Collision avoidance system \\
DIAGN & 0.118 & 0.323 & 61 & Vehicle diagnostics \\
OBCMON & 0.351 & 0.478 & 181 & Onboard computer monitoring \\
SAFEMEET & 0.880 & 0.325 & 454 & Safety meetings \\
FLEETSPEED & 0.800 & 0.400 & 413 & Fleet speed limit \\
APRENT & 0.436 & 0.496 & 225 & Apprenticeship training program \\
OTP & 0.709 & 0.455 & 366 & On-Time performance strategy \\
SAFESTRAT & 0.072 & 0.258 & 37 & Safety performance strategy \\
LTL & 0.107 & 0.309 & 55 & Less-than-truckload carrier \\
UNION & 0.203 & 0.403 & 105 & Unionized firm \\
\hline
\end{tabular}

\section{Continuous Variables}

$\begin{array}{lcc} & \text { Mean } & \text { Std Dev } \\ \text { OOP } & 0.25 & 0.35 \\ \text { SIZE } & 20.35 & 97.51 \\ \text { IARATE } & 66.37 & 157.55 \\ \text { FARATE } & 4.05 & 16.69 \\ \text { IAFARATE } & 70.42 & 163.60\end{array}$

\section{Variable Description}

Owner-operator miles divided by total firm miles

Total assets (thousands of dollars)

Injury accident rate per 100 million VMT

Fatal accident rate per 100 million VMT

Injury and fatal accident rate per 100 million VMT 
avoidance systems (COLLAV) can also be used for monitoring driver performance. Through closed-circuit television, infrared or low frequency radar, COLLAV informs drivers of proximity to obstacles. Automated vehicle diagnostics systems (DIAGN) are yet another in-vehicle technology that can enhance safety through monitoring vehicle operation performance and maintenance activities. Diagnostic and maintenance support systems can assess vehicle performance and assists in creating optimal maintenance schedules (USDOT, 1999, pp. 4-11).

Safety practices, as mentioned in the theory section are generally initiated and implemented by the firm. There are a variety of firm safety practices for managers to choose from. The safety practice variables are all dummy variables indicating whether the firm uses a particular strategy. The data on safety practices, technology use, and marketing strategies is unique, but has limitations. For each of the safety practices a firm uses, there is no additional data to measure quality of the activities of the practices. For example, there is no stated speed limit for firms with fleet speed limits and there is no information on the frequency or length of safety meetings.

The MSCOT survey is also the source of the marketing strategy data. Firms were asked to rank five marketing strategies: lowest freight rate, on-time-performance, short turn around, use of specialized and dedicated equipment, and safety performance. Though there were five options, most carriers can likely be classified as either LFR or OTP. It would be nice to test the dichotomous nature of the LFR and OTP marketing strategy, however the survey method of ranking strategies does not lend itself easily to testing LFR versus OTP firms. In fact, many firms rank OTP and LFR as their first and second marketing strategies, though each strategy clearly requires a different operating approach. Firms with the safety performance marketing strategy (SAFESTRAT) are included in the model. Firms with a marketing strategy of SAFESTRAT cannot have an OTP marketing strategy because the firm could only rank one strategy as their top priority.

The SAFER system collects and disseminates safety data on interstate firms. The SAFER system is one way the Federal
Motor Carrier Safety Administration hopes to use information technology to increase efficiency and safety of motor carrier operations. Currently the SAFER system provides carrier profiles for public information. This allows shippers and the general public access to information on a specific carrier's accident and inspection history for the previous 12-month period. SAFER data is also available in an annual catalog form for data analysis purposes. The 1996 SAFER data used in this study includes number and type of inspections (vehicle, driver, or hazardous), number of out of services, number of accidents (fatal, injury, and hazardous) and the firm's safety rating issued by the FMCSA. This study uses the number of reported fatal, FA, and injury accidents, IA, by firm as reported in the SAFER system.

The use of accident rates in the safety literature has often been criticized primarily because of the lack of reliable truck crash data. The reliability of accident data has been suspect in the past due to firm reporting of the data, and inconsistent reporting standards across states. Even with accurate crash data, some critics argue that accident rates are inappropriate measures of firm safety because crashes involve many factors that are outside of the control of the firm. Beard (1992) cites these reasons in his decision to use inspection rates as proxy for firm safety performance. If safety inspections are closely correlated with accident rates then this may be a good measure. However, inspection rates are not perfectly correlated with accidents. With stricter reporting standards and the creation of the SAFER system, carrier accident data is now much more accurate than it was in the early 1980s. Particularly reliable are data on fatal and injury accidents.

The Fatal Accident Reporting System (FARS) provides detailed information about fatal motor vehicle accidents. FARS is a highly detailed database of fatal motor vehicle crashes in the United States and has been an excellent source of crash causation and environmental factors for fatality crashes. Crash reporting problems of the past are improving with federal reporting standards, FARS, and the SAFER system. The creation of the SAFER system has drastically improved access and the accuracy of motor carrier crash statistics. 
The first empirical model tests the relationship between the firm injury accident (IA) rate and firm characteristics, safety practices, and use of safety technology. The IA model is:

\section{(3) $\operatorname{Ln}($ IARATE $)=$ COLLAV + DIAGN + OBCMON+SAFEMEET+FLEETSPEED + APRENT+OTP+SAFESTRAT+LTL+ $\mathrm{UNION}+\mathrm{OOP}+\mathrm{SIZE}+\mathrm{e}$}

The second model is identical to the first except that it uses the fatal and injury accident rate (FAIA) as the dependent variable.

As discussed in the theory section, the expected signs of the safety practices and technology dummy variables should be negative. Firm characteristics may have either a positive or negative relationship with the firm accident rate.

Following the motor carrier accident rate models of Corsi and Fanara $(1988,1989)$ and Corsi et al. (1984), a semilogarithmic functional form has been chosen for the model. There is no economic theory to suggest a functional form and as these previous papers point out, carrier accident rates are distributed approximately log normal. Use of a semi-log functional form is preferred to the log-log form due to the presence of the variable owner-operator, which is expressed as a ratio. A logarithmic transformation is performed on the dependent variable for the semilogarithmic form. Many carriers had zero injury or fatality accidents reported, thus to perform the logarithmic transformation, a one was added to the number of carrier accidents, then divided by carrier miles to calculate the two different carrier accident rates. Corsi adds one to the accident rate before the logarithmic transformation and notes the possible bias that may result. A mathematical transformation of the coefficients of the dummy variables will correct for most of this bias, and as Corsi and Fanara (1984) point out, given the large sample size, consistency of the estimates is assured. Adding a one to the number of carrier accidents before dividing by carrier miles to create the accident rate likely creates less of a bias than the method of Corsi and Fanara (1988).

A convenient result of using the semilogarithmic functional form is the interpretation of the impact of the various safety practices and firm characteristics. The coefficients of continuous variables can be multiplied by 100 and then interpreted as the percentage effect of that variable on the dependent variable. A mathematical transformation must be performed to interpret the coefficients of the dummy variables as percentage changes.

Kennedy's (1981) approximate unbiased estimator of the percentage change $(\hat{p})$ is used to convert the coefficients of the dummy variables to percentage change. To transform the coefficient into the percentage effect, the OLS estimate of the coefficient of a dummy variable, $\hat{c}$, and the OLS estimate of its variance, $\hat{V}(\hat{c})$, are used in the following equation:

(4) $\hat{p}=\exp \left(\hat{c}-\frac{1}{2} \hat{V}(\hat{c})\right)-1$

A recent addition to the literature on the correct interpretation of dummy variables in semilogarithmic equations is an approximation for an unbiased estimator of variance (Garderen $\&$ Shah 2002, p. 152). Though t-statistics correctly determine the significance of dummy variables in the model, the approximation for an unbiased estimator for the variance is a nice complement for Kennedy's estimator. The estimator for unbiased variance is practical and straightforward to use, and again is a simple transformation using the OLS estimated coefficient and variance. The equation for the approximate unbiased variance estimator is:

(5) $\widetilde{V}(\hat{p})=100^{2} \exp \{2 \hat{c}\}[\exp \{\hat{V}(\hat{c})\} \quad \exp \{2 \hat{V}(\hat{c})\}]$

These equations are used to calculate the Kennedy approximate percentage change and the approximate unbiased variance estimator, which are presented in Table 5. As Garderen and Shah (2002) comment, these approximations are "very simple, yet highly reliable," given the assumption of normal disturbances.

While this model tests many firm safety practices and new safety technologies, as well as several firm characteristics, there are most likely a multitude of other factors that contribute toward carrier accident rates. Omission of relevant variables may bias the estimated coefficients. Data is unavailable for some relevant variables, and it is not clear what other variables should be included in the model. 
As Corsi et. al. (1984) notes, "As long as omitted variables are not correlated with the variables included in our models, omitted variables should not have a substantial influence on the results presented" (p. 162). The possibility of omitted relevant variables seems to be a common problem in regressions involving accident rates due to the variety of factors that contribute to the causation of vehicle accidents.

\section{EMPIRICAL RESULTS}

The results of the injury accident rate (IA) model estimation are shown in Table 2, and the fatality/ injury (FAIA) regression results are shown in Table 3. In general, the results support the theoretical framework of the paper; firms choose safety practices and technology to decrease the carrier accident rate. Four of the 12 variables are found to be significant at the 0.01 confidence level in the IA model; FLEETSPEED, SAFESTRAT, OOP, and UNION. Variables significant at the 0.05 level are: COLLAV and SAFEMEET. All of the coefficients, except for SAFEMEET, have the expected (negative) signs.

Comparing the results of the two regressions, COLLAV is significant in the IA regression at the 0.05 level, however COLLAV is not significant in the FAIA model. The opposite is true for APRENT. APRENT is significant (at the 0.05 level) in the FAIA regression and not significant in the IA regression.

The significantly positive relationship between SAFEMEET and carrier accident rate is inconsistent with theory and prediction. Ex post, an explanation for this result may be that firm safety meetings are an Occupational Safety and Health Administration (OSHA) work rule. Thus, it is possible that many firms implement safety meetings to comply with worker safety laws, which will lead to use of safety meetings even if this practice does not decrease the firm accident rate. Firms with high accident rates may also use the safety meeting safety practice as a remedial tool to help increase their safety performance.

Interestingly, firm characteristics appear to be some of the most significant factors influencing firm accident rates. Three of the most significant negative variables in the model are firm characteristics: safety performance marketing strategy, use of owner-operators, and unionization. Though unionization is declining in the industry, it appears to overwhelmingly reduce carrier accident rates. Use of owneroperators is another firm characteristic that is significantly related to lower carrier accident rates. This result is consistent with the principalagent theory, which suggests that drivers that own their tractor or truck have more incentive to engage in safe driving behavior and safety inducing vehicle maintenance practices. Also consistent with expectations and previous empirical evidence is the negative coefficient on firm size. There were no clear expectations as to the signs of the coefficients of OTP and LTL. Both of these variables have positive coefficients in the regression results, though neither variable is significant.

The significance of the regressions is tested using an F-statistic. Despite low R-squared values, the computed F-statistics are 8.08 for the injury accident rate (IA) regression, and 8.14 for the fatality and injury accident rate (FAIA) regression. The computed F-statistics confirm the significance of both regressions.

The percentage change interpretation of dummy variables is based on Kennedy's unbiased approximate estimator along with standard error and variance from the Garderen and Shah (2002) unbiased approximate estimator of the variance. These results are reported in Tables 4 and 5 .

Some of the percentage effects seem quite dramatic. In particular, COLLAV (controlling for other variables in the model) reduces carrier injury accident rate by more than $50 \%$. While this result seems quite remarkable, the accompanying approximation for unbiased variance and standard error is quite large. This illustrates the value of the newly proposed approximate unbiased estimator for the variance. Caution should be used when interpreting the percentage effects of dummy variables when the estimated variance is large. This is true even when the OLS estimated coefficient is statistically significant (Garderen \& Shah, 2002). Variables with notable percentage changes with relatively low approximated variance are UNION and FLEETSPEED. Both of 
Table 2: Injury Accident Rate Regression Results

\begin{tabular}{|c|c|c|}
\hline Variable & $\begin{array}{c}\text { Regression Coefficient } \\
\text { (Standard Error) }\end{array}$ & $\begin{array}{c}\text { T-Statistic } \\
\text { (Significance) }\end{array}$ \\
\hline \multirow[t]{2}{*}{ COLLAV } & $-0.7225^{*}$ & -1.98 \\
\hline & $(0.36464)$ & $(0.0481)$ \\
\hline \multirow[t]{2}{*}{ DIAGN } & -0.08909 & -0.88 \\
\hline & $(0.10071)$ & $(0.3768)$ \\
\hline \multirow[t]{2}{*}{ OBCMON } & -0.07222 & -1.02 \\
\hline & $(0.07093)$ & $(0.3091)$ \\
\hline \multirow[t]{2}{*}{ SAFEMEET } & $0.27890^{*}$ & 2.80 \\
\hline & $(0.09966)$ & $(0.0053)$ \\
\hline \multirow[t]{2}{*}{ FLEETSPEED } & $-0.31669 * *$ & -3.78 \\
\hline & $(0.08375)$ & $(0.0002)$ \\
\hline \multirow[t]{2}{*}{ APRENT } & -0.11873 & -1.82 \\
\hline & $(0.06540)$ & $(0.0700)$ \\
\hline \multirow[t]{2}{*}{ OTP } & 0.11445 & 1.59 \\
\hline & $(0.07204)$ & $(0.1128)$ \\
\hline \multirow[t]{2}{*}{ SAFESTRAT } & $-0.35961 * *$ & -2.85 \\
\hline & $(0.12619)$ & $(0.0046)$ \\
\hline \multirow[t]{2}{*}{ LTL } & 0.14703 & 1.38 \\
\hline & $(0.10634)$ & $(0.1674)$ \\
\hline \multirow[t]{2}{*}{ OOP } & $-0.32073 * *$ & -3.43 \\
\hline & $(0.09355)$ & $(0.0007)$ \\
\hline \multirow[t]{2}{*}{ UNION } & $-0.38476^{* *}$ & -4.78 \\
\hline & $(0.08052)$ & $(<.0001)$ \\
\hline \multirow[t]{2}{*}{ SIZE } & -0.00052 & -1.55 \\
\hline & $(0.00033)$ & $(0.1206)$ \\
\hline
\end{tabular}

R-Square $=0.1616$

F Statistic $=8.08$

Adj. R-Square $=0.1416$

$\mathrm{N}=516$

* Significant at the 0.05 level

** Significant at the 0.01 level 
Table 3: Injury and Fatality Accident Rate Regression Results

\begin{tabular}{|c|c|c|}
\hline Variable & $\begin{array}{c}\text { Regression Coefficient } \\
\text { (Standard Error) }\end{array}$ & $\begin{array}{c}\text { T-Statistic } \\
\text { (Significance) }\end{array}$ \\
\hline \multirow[t]{2}{*}{ COLLAV } & -0.54231 & -1.53 \\
\hline & $(0.35495)$ & $(0.1272)$ \\
\hline \multirow[t]{2}{*}{ DIAGN } & -0.08844 & -0.90 \\
\hline & $(0.09803)$ & $(0.3674)$ \\
\hline \multirow[t]{2}{*}{ OBCMON } & -0.07609 & -1.10 \\
\hline & $(0.06905)$ & $(0.2710)$ \\
\hline \multirow[t]{2}{*}{ SAFEMEET } & $0.29961 * *$ & 3.09 \\
\hline & $(0.09701)$ & $(0.0021)$ \\
\hline \multirow[t]{2}{*}{ FLEETSPEED } & $-0.31415^{* *}$ & -3.85 \\
\hline & $(0.08153)$ & $(0.0001)$ \\
\hline \multirow[t]{2}{*}{ APRENT } & $-0.13297 *$ & -2.09 \\
\hline & $(0.06366)$ & $(0.0372)$ \\
\hline \multirow[t]{2}{*}{ OTP } & 0.10739 & 1.53 \\
\hline & $(0.07012)$ & $(0.1263)$ \\
\hline \multirow[t]{2}{*}{ SAFESTRAT } & $-0.35727^{* *}$ & -2.91 \\
\hline & $(0.12284)$ & $(0.0038)$ \\
\hline \multirow[t]{2}{*}{ LTL } & 0.18369 & 1.77 \\
\hline & $(0.10351)$ & $(0.0766)$ \\
\hline \multirow[t]{2}{*}{ OOP } & $-0.31519 * *$ & -3.46 \\
\hline & $(0.09106)$ & $(0.0006)$ \\
\hline \multirow[t]{2}{*}{ UNION } & $-0.35258 * *$ & -4.50 \\
\hline & $(0.07838)$ & $(<.0001)$ \\
\hline \multirow[t]{2}{*}{ SIZE } & -0.00055 & -1.68 \\
\hline & $(0.000328)$ & $(0.0929)$ \\
\hline
\end{tabular}

R-Square $=0.1626$

F Statistic $=8.14$

Adj. R-Square $=0.1426$ $\mathrm{N}=516$

* Significant at the 0.05 level

** Significant at the 0.01 level 
these variables have OLS coefficients significant at the 0.01 level and both roughly reduce the firm accident rate by $30 \%$.

Often, when using firm-level data, heteroscedasticity may become a problem due to variation caused by firm size. Goldfeld-Quant and Breusch-Pagan tests for heteroscedasticity were performed on both models to test for this possibility. The Goldfeld-Quant test was performed with respect to the data sorted by firm size (total assets). The resulting GoldfeldQuant statistics from testing the disturbances of a regression of the lower quartile and compared to the disturbances from a regression on the upper quartile of data is $\mathrm{F}[116,116]=0.793$ for the IA model and $F[116,116]=0.792$ for the FAIA model. The critical value is 1.357 , so the hypothesis of homoscedasticity is not rejected. Multiple Breusch-Pagan tests were performed; the first one on the entire set of regressors, then a second test with only the continuous regressors (SIZE and OOP), and a third test on SIZE only. All three of these tests, for both regressions, also fail to reject the hypothesis of homoscedasticity. Based on these tests it is concluded that heteroscedasticity is not a problem for inferences based on the results of this model (Greene, 2000, pp. 507-510).

Table 4: Injury Accident Rate Regression Percentage Effect Results

\begin{tabular}{lccc}
\hline Variable & $\begin{array}{c}\text { Percentage Change } \\
\text { (Kennedy's Approx.) }\end{array}$ & $\begin{array}{c}\text { Standard Error } \\
\text { (Approx. Unbiased Estimator) }\end{array}$ & $\begin{array}{c}\text { Variance } \\
\text { COLLAV }\end{array}$ \\
DIAGN & $8.99 \%$ & 29.76 & 885.81 \\
OBCMON & $7.20 \%$ & 15.92 & 253.34 \\
SAFEMEET & $31.56 \%$ & 11.42 & 130.31 \\
FLEETSPEED & $27.40 \%$ & 22.80 & 519.65 \\
APRENT & $11.38 \%$ & 10.55 & 111.30 \\
OTP & $11.84 \%$ & 10.05 & 100.98 \\
SAFESTRAT & $30.76 \%$ & 13.97 & 195.23 \\
LTL & $15.19 \%$ & 15.19 & 230.89 \\
UNION & $32.16 \%$ & 21.28 & 452.68 \\
\hline
\end{tabular}

Table 5: Injury and Fatality Accident Rate Regression Percentage Effect Results

\begin{tabular}{lccc}
\hline Variable & $\begin{array}{c}\text { Percentage Change } \\
\text { (Kennedy's Approx.) }\end{array}$ & $\begin{array}{c}\text { Standard Error } \\
\text { (Approx. Unbiased Estimator) }\end{array}$ & $\begin{array}{c}\text { Variance } \\
\text { COLLAV }\end{array}$ \\
DIAGN & $85.41 \%$ & 34.74 & 1206.80 \\
OBCMON & $7.55 \%$ & 15.51 & 240.41 \\
SAFEMEET & $34.30 \%$ & 11.07 & 122.55 \\
FLEETSPEED & $27.20 \%$ & 22.62 & 511.64 \\
APRENT & $12.63 \%$ & 10.30 & 106.04 \\
OTP & $11.06 \%$ & 9.64 & 93.00 \\
SAFESTRAT & $30.57 \%$ & 13.51 & 182.40 \\
LTL & $19.52 \%$ & 14.83 & 219.91 \\
UNION & $27.34 \%$ & 21.49 & 461.67 \\
\hline
\end{tabular}




\section{CONCLUSION}

Motor carrier managers have a range of safety practices and technologies to choose among to reduce their carrier accident rate. This paper finds that fleet speed limits, safety performance marketing strategies, apprenticeship training programs, and collision avoidance systems are negatively related to carrier accident rates. The firm characteristics of unionization, safety performance marketing strategy, and use of owner-operators also significantly reduce carrier accident rates. The results find that the safety practice of firm safety meetings is the only variable significantly related to higher firm accident rates.

New technologies in the motor carrier industry promise exciting safety gains in the future. Technology improvements in vehicle construction, particularly vehicle dynamics and braking systems and in-vehicle technologies like collision avoidance systems, adaptive cruise control and camera monitoring of vehicle blind spots, are technologies that are likely to reduce the occurrence of large truck crashes. Additionally, technology will help to reduce the severity of large truck crashes. Crash-severity-reducing technologies include driver crash-protection systems and rear cushioning bumpers. The relatively low adoption rates of such technologies limited the empirical analysis of technologies in this study. As adoption rates increase, it will be important to evaluate the safety effects of new technologies, particularly with respect to the use of technology in government inspection programs.

The results show that firms with the safety performance marketing strategy have significantly lower accident rates. This supports the contention that firm management policies can directly impact the safety performance of the firm. In future studies it would be interesting to examine the cost structure of firms with a safety performance marketing strategy, particularly whether firms are able to recoup additional safety expenditures through rate differentials, reduced insurance costs, and/or reduced accident costs.

This study finds strong evidence that use of owner-operators reduces carrier accident rates. The principal-agent theory, contractual relationships, ownership structure, and firm size are areas for future motor carrier safety research. Though drivers resist monitoring technologies, it is likely that manager incentives to use such technologies will make on-board computers commonplace in the industry. This will likely have a significant impact on use of owner-operators.

It is clear that unions have successfully served their role in providing for worker safety. Evidence has demonstrated that unionized firms have different cost structures than non-unionized firms, resulting in higher firm operating costs (Kerkvliet \& McMullen, 1997). Union participation has declined dramatically since deregulation and as firms struggle to reduce operating costs the trend of decreasing unionization is likely to continue. Though union work rules may restrict operating flexibility, managers should evaluate and then incorporate union rules which increase safety without hurting the competitiveness of the firm.

The results show a significant relationship between fleet speed limits and lower carrier accident rates. Fleet speed limits may reflect a greater 'safety culture' of the firm, but more importantly, this result reinforces the common knowledge that speed is a factor in most serious motor vehicle accidents. Within a ruthlessly competitive industry that strives for on-time performance and short turn-around schedules to meet the shipper needs for fast service and just-in-time inventories, it is important to emphasize the need to drive at reasonable speeds. The significance of firm fleet speed limits also highlights the necessity of adequate highway speed limit enforcement and hours-of-service regulations.

If firm safety meetings are in fact an Occupational Health and Safety Administration work rule, then the positive relationship between safety meetings and carrier accident rates indicates the need to evaluate the effectiveness of such mandatory government regulations. This unpredicted result may also indicate a failure in the data to distinguish between varying levels of activities within the safety practice. For all of the attention motor carrier safety receives-as an industry priority, from the public, and from government safety regulators, there has been relatively little recent literature on the subject. Motor carrier accident rate data is plentiful and independent economic policy evaluation is desperately lacking (Hauer, 1989; Moses \& Savage, 1997). 
This paper reflects research conducted for master's thesis at Oregon State University. The views and opinions of the author expressed herein do not necessarily state or reflect those of the United States Government, the U.S. Department of Transportation, RITA, nor the
Volpe National Transportation Systems Center. The author acknowledges support from the Northwestern University Transportation Center, her master's thesis committee members, and the Journal of the Transportation Research Forum editor and two anonymous referees.

\section{References}

Adams, B. "Deregulation's Negative Effect on Safety." L. Moses and I. Savage eds. Transportation Safety in an Age of Deregulation. New York: Oxford University Press (1989): 21-27.

Alexander, D.L. "Motor Carrier Deregulation and Highway Safety: An Empirical Analysis." Southern Economic Journal 59(1), (1992):28-37.

Beard, R.T. "Financial Aspects of Motor Carrier Safety Inspection Performance.” Review of Industrial Organization 7(1), (1992):51-64.

Boyer, K. "The Safety Effects of Mode Shifting Following Deregulation." L. Moses and I. Savage eds. Transportation Safety in an Age of Deregulation. New York: Oxford University Press (1989):258-276.

Chow, G. "Deregulation, Financial Distress, and Safety in the General Freight Trucking Industry." L. Moses and I. Savage eds. Transportation Safety in an Age of Deregulation. New York: Oxford University Press (1989):219-240.

Corsi, T., P. Fanara, and M. Roberts. "Linkages Between Motor Carrier Accidents and Safety Regulation." Logistics and Transportation Review 20(2), (1984):149-164.

Corsi, T. and P. Fanara. "Driver Management Policies and Motor Carrier Safety." Logistics and Transportation Review 24(2), (1988):153-63.

Corsi, T., P. Fanara, and J. Jarrell. "Safety Performance of Pre-MCA Motor Carriers, 1977 Versus 1984." Transportation Journal 27(3), (1988):30-36.

Corsi, T. and P. Fanara. "Effects of New Entrants on Motor Carrier Safety." L. Moses and I. Savage eds. Transportation Safety in an Age of Deregulation. New York: Oxford University Press (1989):241-257.

Daicoff, D.W. "Deregulation and Motor Carrier Safety." Logistics and Transportation Review 24(2), (1988):175-184.

Garderen, K.J.V. and C. Shah. "Exact Interpretation of Dummy Variables in Semilogarithmic Equations.” Econometrics Journal 5, (2002):149-159.

Golbe, D.L. "Safety and Profits in the Airline Industry." Journal of Industrial Economics 34, (1986):305-318.

Greene, W. Econometric Analysis. Prentice Hall, Upper Saddle River, NJ, 2000. 
Hauer, E. "The Reign of Ignorance in Road Safety: A Case for Separating Evaluation From Implementation." L. Moses and I. Savage eds. Transportation Safety in an Age of Deregulation. New York: Oxford University Press (1989):56-69.

Kaneko, T. and P.P. Jovanis. "Multiday Driving Patterns and Motor Carrier Accident Risk: A Disaggregate Analysis." Accident Analysis and Prevention 24, (1992):437-456.

Kennedy, P.E. "Estimation with Correctly Interpreted Dummy Variables in Semilogarithmic Equations." American Economic Review 71(4), (1981):801.

Kerkvliet, J. and B.S. McMullen. "The Impact of Unionization on Motor Carrier Costs." Economic Inquiry XXXV, (1997):271-284.

Lave, L. "Safety in Transportation: The Role of Government." Law and Contemporary Problems 33, (1968):512-535.

McCarthy, P.S. Transportation Economics. Blackwell Publishers Ltd., Malden, MA, 2001.

Mejza, M.C., R.E. Barnard, T.M. Corsi, and T. Keane. "Driver Management Practices of Motor Carriers with High Compliance and Safety Performance." Transportation Journal 42(4), (2003):16-29.

Mixon, F.G. Jr. and K.P. Upadhyaya. "Principal-Agent Relationships, Asset Specificity, and Motor Carrier Safety: Evidence from Panel Data Estimates.” International Journal of Transport Economics 23, (1996):205-211.

Monaco, K. and E. Williams. "Assessing the Determinants of Safety in the Trucking Industry." Journal of Transportation and Statistics 3(1), (2000):1-11.

Moore, T.G. "Moving Ahead." Regulation 25, (2002):6-13.

Moses L. N. and I. Savage eds. Transportation Safety in an Age of Deregulation. Oxford University Press, New York, 1989.

Moses, L.N. and I. Savage. "The Effectiveness of Motor Carrier Safety Audits." Accident Analysis and Prevention 24, (1992):479-496.

Moses, L.N. and I. Savage. "The Effect of Firm Characteristics on Truck Accidents." Accident Analysis and Prevention 26(2), (1994):173-179.

Moses L.N. and I. Savage. "A Cost-Benefit Analysis of US Motor Carrier Safety Programmes." Journal of Transport Economics and Policy 31, (1997):51-67.

Saltzman, G. and M. Belzer. "The Case for Strengthened Motor Carrier Hours of Service Regulations." Transportation Journal 41(4), (2002):51-71.

Traynor, T.L. and P.S. McCarthy. "Trucking Deregulation and Highway Safety: The Effect of the 1980 Motor Carrier Act.” Journal of Regulatory Economics 3, (1991):339-348. 
Traynor, T.L. and P.S. McCarthy. "Economic Regulation and Highway Safety in the Trucking Industry: A Limited Dependent Variable Analysis." The Quarterly Review of Economics and Finance 33, (1993):141-153.

U.S. Department of Transportation. Office of Motor Carrier Safety. "Motor Carrier TechnologiesFleet Operational Impacts and Implications for Intelligent Transportation Systems/ Commercial Vehicle Operations.” Report No FHWA-MC-00-0005, October 1999.

Williams E. and K. Monaco. "Accidents and Hours-of-Service Violations Among Over-the-Road Drivers." Journal of the Transportation Research Forum 40(1), (2001):105-115.

Sarah J. Dammen received her M.S. degree in economics from Oregon State University in 2003. She currently works as an economist at the Volpe National Transportation Systems Center, Research and Innovative Technology Administration, U.S. Department of Transportation in Cambridge, MA. 